University of Nebraska - Lincoln

DigitalCommons@University of Nebraska - Lincoln

USDA National Wildlife Research Center - Staff Publications
U.S. Department of Agriculture: Animal and Plant Health Inspection Service

March 2003

\title{
Wariness of coyotes to camera traps relative to social status and territory boundaries
}

\author{
E.S. Sequin \\ Department of Biology, Program in Ecology, Evolution and Conservation Biology, University of Nevada at \\ Reno \\ Michael M. Jaeger \\ U.S. Department of Agriculture (USDA), Animal and Plant Health Inspection Service (APHIS), Wildlife \\ Services (WS), National Wildlife Research Center (NWRC), Logan, Utah; Department of Environmental \\ Science, Policy and Managment, University of California at Berkeley, CA \\ Peter F. Brussard \\ Department of Biology, Program in Ecology, Evolution and Conservation Biology, University of Nevada at \\ Reno \\ Reginald H. Barrett \\ Department of Environmental Science, Policy and Management, University of California at Berkeley, CA
}

Follow this and additional works at: https://digitalcommons.unl.edu/icwdm_usdanwrc

Part of the Environmental Sciences Commons

Sequin, E.S.; Jaeger, Michael M.; Brussard, Peter F.; and Barrett, Reginald H., "Wariness of coyotes to camera traps relative to social status and territory boundaries" (2003). USDA National Wildlife Research Center - Staff Publications. 233.

https://digitalcommons.unl.edu/icwdm_usdanwrc/233

This Article is brought to you for free and open access by the U.S. Department of Agriculture: Animal and Plant Health Inspection Service at DigitalCommons@University of Nebraska - Lincoln. It has been accepted for inclusion in USDA National Wildlife Research Center - Staff Publications by an authorized administrator of DigitalCommons@University of Nebraska - Lincoln. 


\title{
Wariness of coyotes to camera traps relative to social status and territory boundaries
}

\author{
Eveline S. Séquin, Michael M. Jaeger, Peter F. Brussard, and Reginald H. Barrett
}

\begin{abstract}
The primary objective of this study was to develop a better understanding of coyote (Canis latrans) wariness particularly as it related to social status. We determined that territory status (controlling alpha, resident beta, or nonterritorial transient) affected vulnerability to photo-capture by infrared-triggered camera systems. All coyotes were wary of cameras, leading to relatively low numbers of photo-captures, most of which occurred at night. Alphas were significantly underrepresented in photographs and were never photo-captured inside their own territories. Betas were photographed inside and outside their territories, whereas transients were most often photographed on edges of territories. Both alphas and betas were photographed more often on territorial edges when outside their territories. We next addressed the question of how alphas were better able to avoid photo-capture. Alphas tracked human activity within their territories and presumably learned the locations of cameras as they were being set up. They did this either by approaching our location directly or by moving to a vantage point from where they could observe us. Betas and transients either withdrew or did not respond to human activity. Trials in which a dog was present were more likely to elicit an approach response from alphas. Avoidance of camera stations and the tracking of human activity implied wariness toward objects or locations resulting from their learned association with human presence rather than neophobia toward the objects themselves.
\end{abstract}

Résumé : L'objectif premier de notre étude est d'obtenir une meilleure compréhension de la méfiance chez les coyotes (Canis latrans), particulièrement en fonction de leur statut social. Le statut territorial (alpha contrôlant, bêta résidant, ou errant non territorial) affecte la vulnérabilité à la prise en photo par un système de caméras déclenchées par infrarouge. Tous les coyotes sont méfiants vis à vis des caméras; il y a donc peu de prises de photos, la plupart pendant la nuit. Les coyotes alpha sont significativement sous représentés sur les photos et ne sont jamais photographiés à l'intérieur de leur territoire. Les coyotes bêta sont photographiés à l'intérieur et à l'extérieur de leur territoire et les errants sont surtout photographiés en bordure des territoires. Lorsqu'ils sont photographiés hors de leur territoire, les coyotes alpha et bêta le sont surtout près des bordures. Nous avons ensuite essayé de déterminer comment les coyotes alpha réussissent mieux que les autres à éviter la caméra. Les coyotes alpha suivent l'activité humaine à l'intérieur de leur territoire et apprennent sans doute l'emplacement des caméras lors de l'installation. Ils s'approchent alors directement de notre position ou alors ils se postent à des sites avantageux pour nous observer. En présence d'activité humaine, les coyotes bêta et errants se retirent ou alors ne réagissent pas. Les essais en présence d'un chien sont plus susceptibles de provoquer une réaction d'approche chez les coyotes alpha. L'évitement des stations de caméras et l'observation de l'activité humaine par les coyotes impliquent une méfiance vis à vis des objets ou des sites qu'ils ont appris à associer à la présence humaine, plutôt qu'une néophobie des objets eux-mêmes.

[Traduit par la Rédaction]

\section{Introduction}

The coyote (Canis latrans) has been both revered and cursed for its intelligence, evasiveness, and adaptability (Bekoff 1978). It is these qualities and the coyote's great flexibility in habitat requirements, together with its ability to live in close association with humans, that have enabled it to thrive and continue to expand its geographic range (Gompper 2002). Consequently, the coyote has become one of the most successful and widely distributed predators in North America (Bekoff and Wells 1986) and has long been a problem for livcstock producers (Wagner 1988; National Agricultural Statistics Service 1995). In an attempt to find a solution to the depredation problem, a considerable amount

Received 9 June 2003. Accepted 12 November 2003. Published on the NRC Research Press Web site at http://cjz.nrc.ca on 22 January 2004.

E.S. Séquin ${ }^{1}$ and P.F. Brussard. Department of Biology, Program in Ecology, Evolution and Conservation Biology, University of Nevada at Reno, Reno, NV 89557, U.S.A.

M.M. Jaeger. U.S. Department of Agriculture (USDA), Animal and Plant Health Inspection Service (APHIS), Wildlife Services (WS), National Wildlife Research Center (NWRC), Logan, Utah 84322, U.S.A., and Department of Environmental Science, Policy and Management, University of California at Berkeley, Berkeley, CA 94720, U.S.A.

R.H. Barrett. Department of Environmental Science, Policy and Management, University of California at Berkeley, Berkeley, CA 94720 , U.S.A.

${ }^{\mathrm{I} C}$ orresponding author (e-mail: esequin@unr.nevada.edu). 
of research has been done on the effects of population reduction and on methods of control (Knowlton et al. 1999). However, relatively little is known about coyote behavior toward control devices other than the fact that capture of the territorial dominant coyotes (alphas) can be relatively difficult (Sacks et al. 1999b). Since evidence suggests that alphas are the principal killers of sheep (Blejwas et al. 2002), the focus of this study was to develop a better understanding of coyote wariness particularly as it relates to alphas. We define wariness as caution toward a situation (i.e., food, object, time, or place) because of its association with the threat of capture (e.g., by a lion, a human, or another coyote).

The alpha pair are the dominant breeding coyotes within a territory (e.g., Gese et al. 1996a; Blejwas et al. 2002). They typically live in family groups together with the nondispersing young of the previous year or two (betas) and pups (e.g., Gese and Ruff 1997, 1998). Pack sizes can vary from 2 (the alpha pair) to 12 or more members; however, 4-6 individuals are most common (e.g., Allen et al. 1987). Territories are exclusive (Knowlton et al. 1999), are maintained year-round (Gantz 1990; Shivik et al. 1996), and are spaced contiguously with prominent landscape features often serving as territorial boundaries (Bekoff and Wells 1986; Windberg and Knowlton 1988; Gese et al. 1996a, 1996b). Unlike alphas and betas, transient coyotes do not reside in territories and usually travel alone (Messier and Barrette 1982; Andelt 1985; Bekoff and Wells 1986; Gese et al. $1989,1996 a$ ). They typically use larger areas than alphas and betas, and overlap their use with other transient and resident animals (e.g., Kamler and Gipson 2000). Transient coyotes have been noted to travel most frequently along the boundaries of territories (Windberg and Knowlton 1988; Sacks et al. 1999a; Kamler and Gipson 2000) and can compose a significant proportion of the coyote population of a region (Gese et al. 1996a).

Evidence suggests that alpha coyotes are less vulnerable to capture with traps and snares than betas or transients (Sacks et al. 1999b). They are relatively more difficult to capture within their own territories (e.g., Woodruff and Keller 1982; Harris 1983; Windberg and Knowlton 1990; Windberg 1996; Sacks et al. 1999b) and are relatively more difficult to capture prior to whelping and the need to provision pups (Sacks et al. 1999b). Similarly, in black-backed jackals (Canis mesomelus), older animals (i.e., alphas) are more successful at avoiding capture (Brand et al. 1995; Brand and Nel 1997). Reduced vulnerability toward capture within their own territories implies that alphas learn about their surroundings, detect devices, and recognize them as foreign. This is supported by studies reporting that captive coyotes readily investigate novel objects in unfamiliar places but are cautious toward these same objects when they are encountered in more familiar areas (Windberg 1996; Harris and Knowlton 2001). In addition, resident coyotes have been shown to be more likely to visit scent stations outside their territories or in less familiar areas (Harris 1983; Harris and Knowlton 2001). Therefore, responses toward novel objects seem to depend on the location of objects in relation to territory boundaries (Lehner et al. 1976). The above studies distinguished between resident (i.e., alphas and betas) and nonresident (i.e., transients) coyotes but not among social classes. In addition, these studies tested "neutral" objects that may have been ignored rather than avoided. Furthermore, they assumed that avoidance or caution toward an object only represented neophobia toward the object itself rather than toward the object together with the human activity and scent associated with it.

The primary objective of this study was to investigate wariness in coyotes toward simulated capture and the human activity associated with it. Specifically. we wanted to determine whether territory status as a controlling alpha, resident beta, or nonterritorial transient affected vulnerability to photo-capture by infrared-triggered camera systems. We also wanted to determine if vulnerability was affected by the location of the camera station relative to territory boundaries. Finally, we wanted to determine if coyotes attended to human presence associated with the setup and maintenance of camera stations.

\section{Methods}

\section{Study area}

This study was conducted on the 15180 ha Grey Davis Dye Creek Preserve of the Nature Conservancy near Red Bluff, California $\left(40^{\circ} 07^{\prime} \mathrm{N}, 121^{\circ} 45^{\prime} \mathrm{W}\right)$. The preserve lies at the edge of the northern Sacramento Valley in the foothills of the Cascade Range at an elevation of $50-700 \mathrm{~m}$. Lower elevations are predominantly annual grasslands, while hills and ridges are covered in blue oak (Quercus douglasii) woodland. Coyote territories used in this study were on an open plain and in the bordering hills. The preserve was closed to the public, and the majority of wildlife was protected, with the exception of a hunting operation that offered guided hunts of deer, pigs, and game birds. Coyotes on the preserve were not hunted and generally represented an unexploited population. However, since 1998, coyotes have been exposed to intermittent capture for radio-collaring, and a few coyotes have been killed by poachers.

\section{Coyote status and territories}

Coyotes on Dye Creek Preserve were captured and marked with individually colored radio-collars and ear tags beginning in 1998 (B. Mitchell, unpublished data). At the time coyotes were physically captured, breeding females, noted by visible nipples or lactation, were considered potential alphas. Their status was confirmed by subsequent radiotelemetry locations and observations of pups at den sites. Males were considered alphas if they were territorial, spent a majority of their time with alpha females, and associated with pups at den sites (e.g., Blejwas et al. 2002). Betas were defined as adult, resident, nonbreeding animals, and transients were defined as nonterritorial adults. Pups remaining in territories were classified as betas at 1 year of age. Trapped and radio-collared coyotes were aged at the time of capture, both by tooth wear (Gier 1968) and by tooth cementum annulus analysis (Linhart and Knowlton 1967).

Territories were determined by radiotelemetry locations before the onset of this study (B. Mitchell, unpublished data). We calculated adaptive kernel (Worton 1989) $90 \%$ home-range estimates for use as territorial boundaries. We designated the core of a territory as falling within the $50 \%$ isopleth and the edge of a territory as outside the $75 \%$ 
Table 1. Description of camera trials conducted in five coyote (Canis latrans) territories near Red Bluff, California.

\begin{tabular}{|c|c|c|c|c|c|c|c|c|c|}
\hline \multirow[b]{3}{*}{ Trial } & \multirow[b]{3}{*}{ Dates } & & & \multicolumn{5}{|l|}{ Camera stations } & \multirow[b]{3}{*}{ Adult photo-captures } \\
\hline & & \multicolumn{2}{|c|}{ Territories* } & \multirow[b]{2}{*}{ Territory coverage } & \multicolumn{2}{|c|}{ Number } & \multicolumn{2}{|c|}{ Density $\left(\mathrm{km}^{2}\right)$} & \\
\hline & & $\mathrm{I}$ & II & & I & II & I & II & \\
\hline 2 & Nov.-Dec. 1999 & 2 & 3 & All & 10 & 29 & 2 & 6 & 23 \\
\hline 3 & May-June 2000 & 3 & 1 & First half & 18 & 15 & 8 & 8 & 15 \\
\hline 4 & July-Aug. 2000 & 3 & 1 & Second half & 18 & 15 & 8 & 8 & 23 \\
\hline 6 & Feb.-Mar. 2001 & 4 & 5 & Second half & 10 & 10 & 2 & 2 & 11 \\
\hline 7 & Apr.-May 2001 & 2 & 5 & All & 2 & 3 & 0.5 & 0.5 & 10 \\
\hline 8 & May-July 2001 & 5 & 4 & All & 20 & 20 & 4 & 4 & 5 \\
\hline
\end{tabular}

* Separate data on the two individual territories used in each trial.

isopleth. Territories ranged in size from 4 to $6 \mathrm{~km}^{2}$. We selected five territories with collared alpha coyotes for camera sessions. These five territories included marked coyotes belonging to all status groups and covered a $40-\mathrm{km}^{2}$ area. Capture and handling of coyotes were done in accordance with study protocols of the University of California at Berkeley (R139, R190) and the USDA/APHIS/WS/NWRC (QA-586), and a memorandum of understanding with the California Department of Fish and Game.

\section{Photo sessions}

Photo sessions were conducted in eight 6-week periods between September 1999 and July 2001 (Table 1). All sessions were separated by at least 1 week when no cameras were in the field. During each session, cameras were placed into two territories with individually marked alpha coyotes. A $0.25-\mathrm{km}^{2}$ grid was overlaid on each selected territory and equal numbers of cameras were placed in each grid square ensuring an even distribution of cameras across territories. Cameras were placed along roads or game trails where we had observed coyotes or their sign (tracks, scat (feces), or fur). During four of the sessions, territories were divided in two (two east-west and two north-south) and cameras were set up in only half of each territory (Table 1). This was done to see if territorial coyotes avoided areas with cameras and spent more time in the half without them.

We used infrared-triggered, commercially made Trailmaster TM-1500 active camera trap units (Goodson and Associates Inc., Lenexa, Kans.) that consisted of a 35-mm weather-resistant camera, an infrared transmitter, and a receiver (Kucera and Barrett 1993). The camera was triggered when the infrared beam was interrupted, and the receiver noted the date, time, and number of interruptions. We used 400-ASA print film with 24 exposures in two types of cameras, Yashika AW-Mini (Yashica Corp., Japan, modified by Goodson and Associates Inc.) and Olympus Twin (Olympus Corp., Tokyo, Japan). During initial setup, cotton gloves were worn to reduce the amount of human scent left on the equipment. Camera units were attached to wooden stakes or secured to vegetation so that the infrared beam was set at a height of approximately $0.25 \mathrm{~m}$. The transmitter was placed between 1.5 and $5 \mathrm{~m}$ from the receiver across dirt roads or game trails. We set the cameras to trigger if the beam was blocked for at least $1 \mathrm{~s}$ with a minimum delay of $1 \mathrm{~min}$ between successive photographs. Cords running between receivers and cameras were covered in aluminum foil and buried under rocks to discourage rodents and feral pigs from chewing on them. Cameras were set to be active $24 \mathrm{~h} /$ day. Camera stations were neither baited nor scented. After initial placement, camera locations were visited once a week to check on the condition of batteries, film, and general setup. If needed, cameras were realigned and batteries and film were changed. Time spent at stations was minimized to reduce scent left at the sites, but cotton gloves were not always worn during the checks. To determine whether alpha coyotes approached cameras without being photo-captured, we placed an SRX_400 Lotek receiver (Lotek Engineering Inc., Newmarket, Ont.) at randomly selected camera stations during sessions 3 through 8 . An equal number of sites were selected in each territory. The receiver was moved weekly and was set to scan continuously the frequencies of all radiocollared alphas within a radius of $10-15 \mathrm{~m}$. The unit was covered in vegetation and hidden as close to camera stations as possible. Data were collected during the weekly checks.

Visual observations were conducted during the camera sessions to determine the proportions of alpha individuals versus individuals of other status in the coyote population. A $0.25-\mathrm{km}^{2}$ grid was placed over the territories and the center of each quadrat was used as an observation location. Observations were made randomly from each location twice during each session, once at dawn and once at dusk. Dawn sessions were begun by hiking to the observation site no later than $1 \mathrm{~h}$ before sunrise, and dusk sessions were begun $0.5 \mathrm{~h}$ before sunset. Each session lasted approximately $1.5 \mathrm{~h}$. Numbers of alphas and other coyotes seen were recorded. The ratio of alphas to other adults was used as the proportion available for capture by camera. Photographs were enlarged to look at collar colors and ear tags. We also identified individuals by pelage patterns on tails, backs, and muzzles (Séquin 2001). Numbers and status of coyotes caught on film were compared with the numbers of coyotes observed in the field using $\chi^{2}$ tests of independence. Phototrapping success was calculated as the total number of photo-captures divided by the total number of active camera nights.

\section{Response to human presence}

To test the hypothesis that alphas tracked our activity, we monitored whether radio-collared coyotes approached, withdrew, did not respond, or moved to a vantage point in response to humans setting up camera stations. Additionally, since dogs have commonly been used by trappers to elicit 
approach responses by coyotes, we used a domestic dog to determine if coyotes responded differently to a human alone versus one with a dog.

Trials were conducted May-July of 2001 in two coyote territories with individually marked, radio-collared alpha animals. One of three beta individuals in one territory (there were no betas in the other territory) and a number of transients in the vicinity of the two territories were also radio-collared. The two additional resident betas were recognizable by their distinct pelage patterns. A $0.25-\mathrm{km}^{2}$ grid was placed over the territories and one central camera location per grid square was chosen at locations of coyote sign (tracks, scat, or fur) for a total of 20 camera locations per territory. For 10 days, we set up two camera stations per territory, two at dawn (0500-0900) in one territory and two at dusk (1800-2200) in the other, allowing us two trials per day. We randomly selected which territory was used in the morning (day 1, morning in $\mathrm{A}$, evening in $\mathrm{B}$; day 2 , morning in $\mathrm{B}$, evening in $\mathrm{A}$; etc.). During half the trials, the researcher was accompanied by a 2-year-old male border collie.

Trials were conducted by one researcher. The first hour of every trial was used to locate radio-collared coyotes by radiotelemetry. This was done with minimal driving or hiking and without entering the selected territory. During the second hour, two cameras were set up at predetermined locations within the territory. Periodic radiotelemetry bearings and visual observations were made during the setup process. Coyote positions were located first by radiotelemetry and then if possible with binoculars. After setup, the researcher moved $500 \mathrm{~m}$ to $1 \mathrm{~km}$ away within the same territory to an observation location overlooking the new camera sites. Coyote movement and responses were tracked from this location for at least $2 \mathrm{~h}$. The entire trial lasted at least $4 \mathrm{~h}$.

After all cameras were placed (10 days), they were allowed to run for 21 days ( $24 \mathrm{~h} /$ day) before removal began (10 days). We checked cameras once a week, during the middle of the day, to inspect their conditions. The dog was not taken on these inspections. At the end of the 3-week period, trials were begun again, this time removing cameras two at a time using the same method and order as during setup. All cameras remained in operation for an equal length of time (i.e., 31 days). A receiver was placed at random camera stations to determine if alpha coyotes visited the camera stations after the researcher departed. For 4 weeks following the end of the camera session, we continued to move the receiver among locations that held cameras, changing the location every $4-5$ days.

\section{Results}

\section{Observation sessions}

Coyotes were seen a total of 332 times during the dawn and dusk observation sessions with an alpha to beta and transient ratio of 1:1.6. Total observation time was $286 \mathrm{~h}$. Coyotes belonging to every status group were observed using dirt roads and game trails. There were no significant differences among status groups in on-trail/road versus off-trail/road observations ( $\chi^{2}$ test, $\chi_{2}^{2}=2.68, P=0.26$ ). We were able to recognize and distinguish additional individuals without collars by their distinct pelage markings and pack associations. Observations over time allowed us to establish the number of individuals in each pack, the number of pups born each season, and the approximate number of transients in the area. This resulted in an estimated alpha to beta and transient ratio of $1: 2$. We chose to use the more objective estimate of 1:1.6 for our analyses. Depending on the season, the estimated coyote density at Dye Creek was $0.8-1.2 / \mathrm{km}^{2}$ (B. Mitchell, unpublished data), which is intermediate among reported estimates from other localities (Knowlton et al. 1999). Territory sizes averaged $4-6 \mathrm{~km}^{2}$, which were similar to other areas of low exploitation with relatively abundant food resources year-round (Andelt 1985; Windberg and Knowlton 1988; Kamler and Gipson 2000). The same alpha animals remained dominant during the entire study. Beta numbers remained relatively constant, while transient and pup numbers increased and decreased with the seasons.

\section{Photo sessions}

Cameras were run for 9702 trap nights with a phototrapping success rate of $1.6 \%$. Coyotes were photo-captured during each camera session, during every season, and at all camera densities (Table 1). The same coyote was never photo-captured at the same camera station more than once within the same hour. Only once was the same coyote photocaptured twice at the same camera station within $24 \mathrm{~h}$. We obtained 106 photographs of adult coyotes including 42 photographs of animals of known status (Fig. 1). The marked sample included 18 photographs of radio-collared animals representing nine different individuals. Additional matching of photographs provided us with 29 more adult individuals for a total of 38 individual coyotes. Fourteen photographed animals were of unknown status (either beta or transient). Radio-collared coyotes were photo-captured in low numbers, but not significantly lower than expected $\left(\chi_{1}^{2}=2.23, P=\right.$ $0.14)$ based on the ratio of radio-collared $(n=18)$ to approximate total coyotes $(n=38)$ in the study area. Photo-trapping success rates of adult coyotes did not differ between early $(1-4)$ and late sessions $(5-8)\left(\chi_{1}^{2}=0.176, P=0.675\right)$. There was no effect of age, which ranged from 1 to 6 years, on photo-capture of radio-collared coyotes $\left(\chi_{5}^{2}=4.61, P=\right.$ 0.466 ). Although cameras operated $24 \mathrm{~h} / \mathrm{day}, 83 \%$ of adult photo-captures occurred between sunset and sunrise $\left(\chi_{1}^{2}=\right.$ 45.79, $P<0.001$ ).

The ratio of photo-captured alphas to betas and transients was 1:34 compared with the expected ratio of 1:1.6 (Fig. 1). Alphas, therefore, were significantly underrepresented in the photo-captures $\left(\chi_{1}^{2}=43.68, P<0.001\right)$. This was still the case when only photographs of radio-collared individuals were considered $\left(\chi_{1}^{2}=3.74, P=0.052\right)$. All three photographs of alphas (representing two individuals) were from camera stations outside their own territories (Fig. 2). However, receivers recorded alphas close to cameras within their territories nine times from a total of 210 receiver nights. Alpha coyotes continued to use both halves of their territories when cameras were placed into one half. The relative use of each half of their territory (based on both telemetry and observation) did not differ from that before the introduction of cameras $\left(\chi_{1}^{2}=1.79, P=0.18\right)$.

Transient coyotes were most often photographed on the edges of territories $\left(\chi_{1}^{2}=8.00, P=0.005\right)$, while betas were photographed both inside and outside their own territories 
Fig. 1. Numbers of photographs by coyote (Canis latrans) status group. (A) When all photographs were used, betas and transients were grouped as "other adults", since not all were radio-collared. (B) A total of 42 photographs of coyotes of known status were photo-captured representing 38 individuals. Alphas were significantly underrepresented in the photo-captures $\left(\chi^{2}\right.$ test: $\chi_{1}^{2}=$ 43.68, $P<0.001)$.
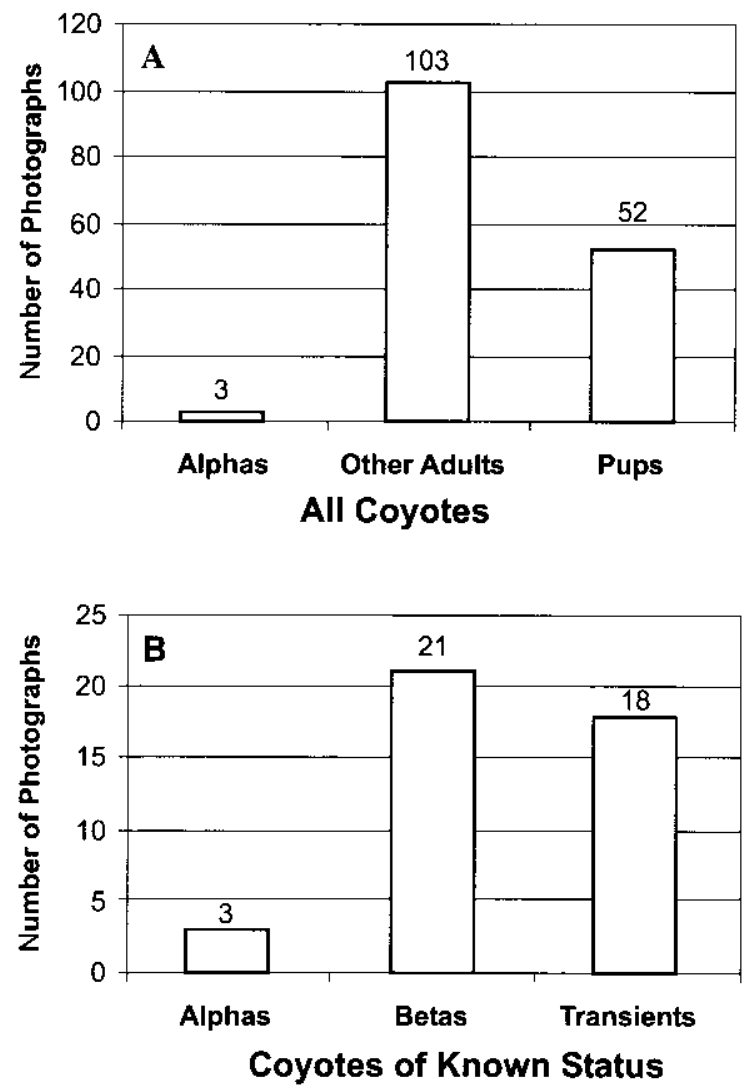

$\left(\chi_{1}^{2}=0.76, P=0.38\right)$. When photographed outside their territories, betas, like transients, were more likely to be photocaptured on the edges $\left(\chi_{1}^{2}=3.60, P=0.058\right.$ ) (Fig. 2). Only $16 \%(17 / 106)$ of adult photo-captures occurred within the $50 \%$ isopleth, while $63.2 \%(67 / 106)$ of adult photo-captures occurred outside the $75 \%$ isopleth. Significantly more photocaptures occurred along territory boundaries $\left(\chi_{1}^{2}=83.71\right.$, $P<0.001$ ). The number of photo-captures of adult coyotes increased as distance from the center of the territory increased (discrete $t$ test, $t_{105}=1.88, P=0.031$ ). Twenty-four percent of camera stations were located at sites that regularly had human activity associated with them (i.e., gates, buildings, and power towers). We found that adult coyotes were more likely to be photographed at these camera stations $\left(\chi_{1}^{2}=16.45, P<0.001\right)$.

\section{Response to human presence}

Alphas responded to human presence (either by approaching, moving to a vantage point, or withdrawing) during $85 \%$ $(34 / 40)$ of trials (Table 2$)$. Setup and removal trials provided similar results $\left(\chi_{1}^{2}=0.11, P=0.741\right)$. There were no differences in responses between the two territories $\left(\chi_{1}^{2}=0.66\right.$, $P=0.416)$ or between morning and evening setup $\left(\chi_{1}^{2}=\right.$ $0.12, P=0.724)$, so trials were grouped as one set of 40 . Alphas either approached the researcher directly (Figs. 3A and
3B) or moved their location to a vantage point from where they could observe the setup process (Figs. 3C and 3D). Typically, only one alpha responded during the trials $(82 \%$ of alpha responses) rather than both alphas. Males and females did not significantly differ in their response rates $\left(\chi_{1}^{2}=0.48, P=0.485\right)$, with both sexes demonstrating direct approach and vantage point responses. When both alphas responded, we considered it as one approach or vantage point response. Number of approaches, retreats, and vantage point responses did not differ between weeks and continued throughout the 40 trials $\left(\chi_{6}^{2}=1.8, P=0.94\right)$. Although camera systems were periodically placed into territories over the course of 2 years, alphas did not habituate to our presence within their territories. Alphas were the only individuals that approached the setup and observation locations directly $\left(\chi_{1}^{2}=16.36, P<0.001\right)$ (Table 2$)$. When alphas approached the researcher, it was generally to a distance of approximately $400 \mathrm{~m}$. Alphas also moved to vantage points more often than coyotes of other status $\left(\chi_{1}^{2}=22.52, P<0.001\right)$. Vantage points were usually on hillsides or rises above camera stations at distances varying from approximately $500 \mathrm{~m}$ to $2 \mathrm{~km}$. Alphas responded in these ways to human activity only within their own territories. On two occasions, betas were nearby as cameras were being set up. However, this was not the result of them approaching (Fig. 3E). Transients never remained close enough to observe us (Fig. 3F). There were five trials during which a researcher working on a different project happened to be in the study territory. Using an expected ratio of approaches and vantage points from trials when only the researcher with this study was present, we found that alphas were more likely to go to a vantage point when two separate humans were in the territory instead of approaching the researcher associated with the camera station $\left(\chi_{1}^{2}=10.89, P<0.001\right)$ (Fig. 3D). Alphas responded to the location of the researcher and not only to that of the cameras. Instead of attending to the camera sites, alphas followed the onward movement of the researcher to the observation point (Figs. 3A-3C).

Receivers recorded alpha individuals at camera locations four times during 70 receiver nights, all of which occurred at least a week after the initial placement of the camera. Only one alpha was recorded at a camera site after the camera had been removed from the field. This occurred 2 days after removal. Additionally, lack of fresh coyote tracks at former camera locations also supported the fact that coyotes did not investigate sites from which cameras had been removed. Dog trials were more likely to elicit direct approaches rather than vantage point responses from alphas $\left(\chi_{1}^{2}=5.02, P=\right.$ 0.025 ). Average approach distances from the researcher and dog were visually estimated and averaged $150 \mathrm{~m}$. Dog trials also elicited more vocal responses $\left(\chi_{1}^{2}=9.55, P=0.002\right)$ than trials without the dog. However, the presence of the dog at camera stations during setup did not significantly affect photo-trap success $\left(\chi_{1}^{2}=0.20, P=0.65\right)$.

\section{Discussion}

\section{Photo-captures}

Social status influenced the vulnerability of coyotes to photo-capture. In addition to being significantly underrepresented in the photographic sample (Fig. 4), alphas were 
Fig. 2. Locations of photo-captures of marked coyotes by status group in relation to territory boundaries. Shading shows the topography of the area and lines represent dirt roads on the preserve. T, transient; B2, beta from territory 2; A4, alpha from territory 4; etc. All B2s are not necessarily the same animal; they refer to any beta from territory 2 .

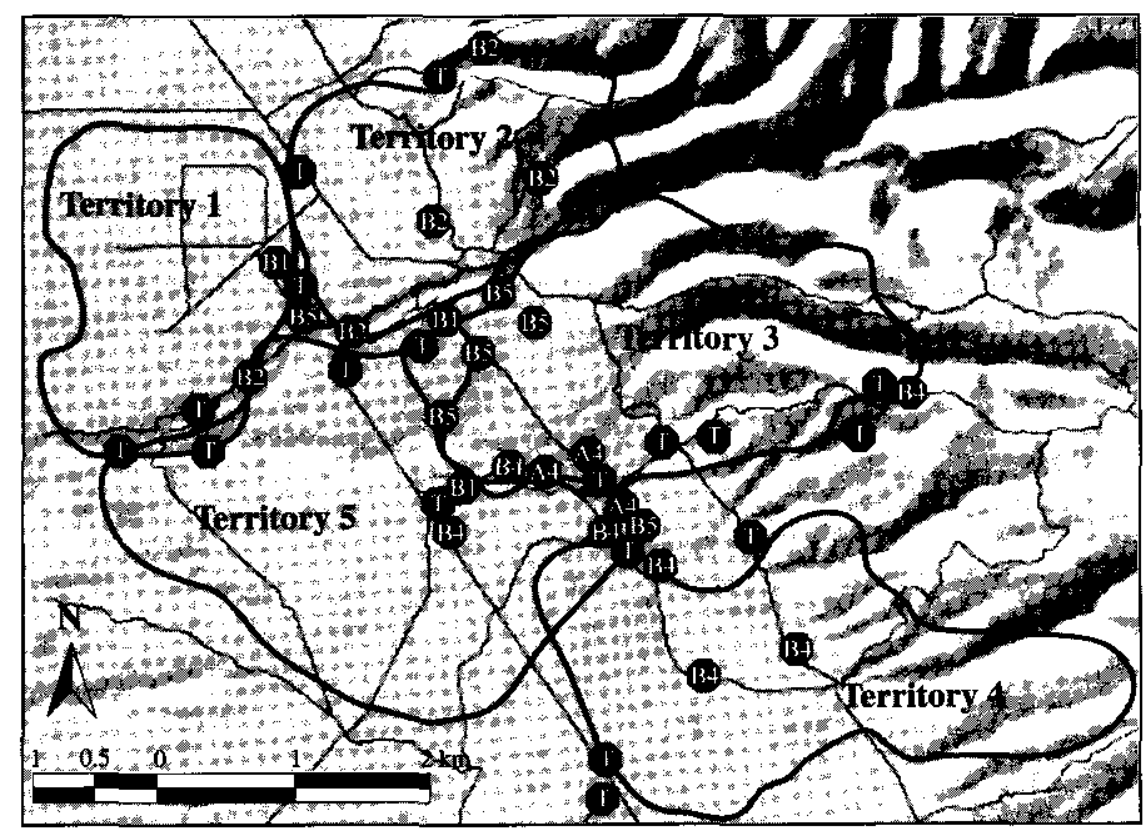

Table 2. Coyote responses to human activity.

\begin{tabular}{|c|c|c|c|c|c|c|c|c|c|c|c|c|c|}
\hline \multirow[b]{2}{*}{ Status } & \multirow[b]{2}{*}{ No. of trials } & \multicolumn{3}{|c|}{ Direct approach } & \multicolumn{3}{|c|}{ Vantage point } & \multicolumn{3}{|c|}{ Withdraw } & \multicolumn{3}{|c|}{ No response } \\
\hline & & $\mathrm{R}$ & RwD & Total & $\mathrm{R}$ & RwD & Total & $\mathrm{R}$ & $R w D$ & Total & $\mathrm{R}$ & RwD & Total \\
\hline Alpha & 40 & 4 & 8 & 12 & 11 & 8 & 19 & 2 & 1 & 3 & 3 & 3 & 6 \\
\hline Transient & 12 & 0 & 0 & 0 & 0 & 0 & 0 & 3 & 5 & 8 & 2 & 2 & 4 \\
\hline
\end{tabular}

Note: Trials focused on alpha individuals and included betas and transients that were available in the selected territories. Number of trials refers to the number of trials in which individuals of a particular status were involved. Trials were conducted by a researcher alone $(\mathrm{R})(n=20)$ and by a researcher with a $\operatorname{dog}(\mathrm{RwD})(n=20)$. Alphas were the only individuals that tracked human activity by approaching the setup and observation locations directly $\left(\chi^{2}\right.$ test: $\chi_{1}^{2}=16.36, P<0.001$ ). Alphas also moved to vantage points from where they could observe human activity more often than coyotes of other status $\left(\chi_{1}^{2}=22.52, P<0.001\right)$. Betas and transients generally withdrew or did not respond to human presence.

never photographed within their own territories (Fig. 2). Betas also were photographed more often outside their territories, but unlike alphas, they were photographed inside their own territories as well. Additionally, when photo-captured outside their areas, both alphas and betas were generally not intruding on other territories but rather were along boundaries. Photo-captures of nonterritorial transients occurred almost exclusively along the boundaries of territories, supporting other studies which showed that transients tend to avoid territory cores (Windberg and Knowlton 1988; Sacks et al. 1999a; Kamler and Gipson 2000). Furthermore, the results of this study are consistent with those of other studies that reported that alphas are relatively difficult to trap within their territories (Messier and Barrette 1982; Sacks et al. 1999b).

We found no evidence that alphas were underrepresented because of their being less likely than betas and transients to use roads and trails along which cameras were placed. Alphas were observed along roads and trails throughout the study, and coyote scats were often found along sections of road where they probably served to advertise the presence of individual coyotes, particularly alphas. Many of the cameras were placed at scat piles that would have been of special in- terest to alpha animals (Gese 1999). If a bias existed at these sites, we would have expected it to favor photo-capture of alphas. In addition, we determined that alphas continued to use areas once cameras had been installed. Both telemetry information from another ongoing study and direct observations confirmed that alpha individuals remained in the vicinity of cameras and that spatial use of territories did not change. This was further demonstrated in sessions where cameras were placed in only one half of each territory. During all of these sessions, coyotes continued to use their entire territories during both day and night and did not avoid the half with cameras. In addition, receivers recorded alphas within $15 \mathrm{~m}$ of camera stations in their territories, although the alpha was not photographed in any of these instances.

Evidence suggests that the difference between alphas and others in vulnerability to photo-capture was not due simply to age and experience. From data collected at the time coyotes were physically captured, we were able to extrapolate the ages of radio-collared individuals at the time they were photographed. If older coyotes were better able to avoid cameras, or if younger animals showed greater curiosity or inexperience, we would have expected to find a higher proportion of photo-captures being of younger animals. How- 
Fig. 3. Responses of coyotes to human presence. Alphas either approached our location directly (A and B) or moved to a vantage point $(\mathrm{C}$ and $\mathrm{D})$. They were more likely to move to a vantage point when other researchers were in the territory, at which point they often moved to a location from where all human activity could be observed (D). (E) Both times that betas observed the researcher, they were already at the camera site and stayed to observe the process. Transients never approached and never moved to vantage points to observe the setup process. (F) A typical transient reaction is shown.
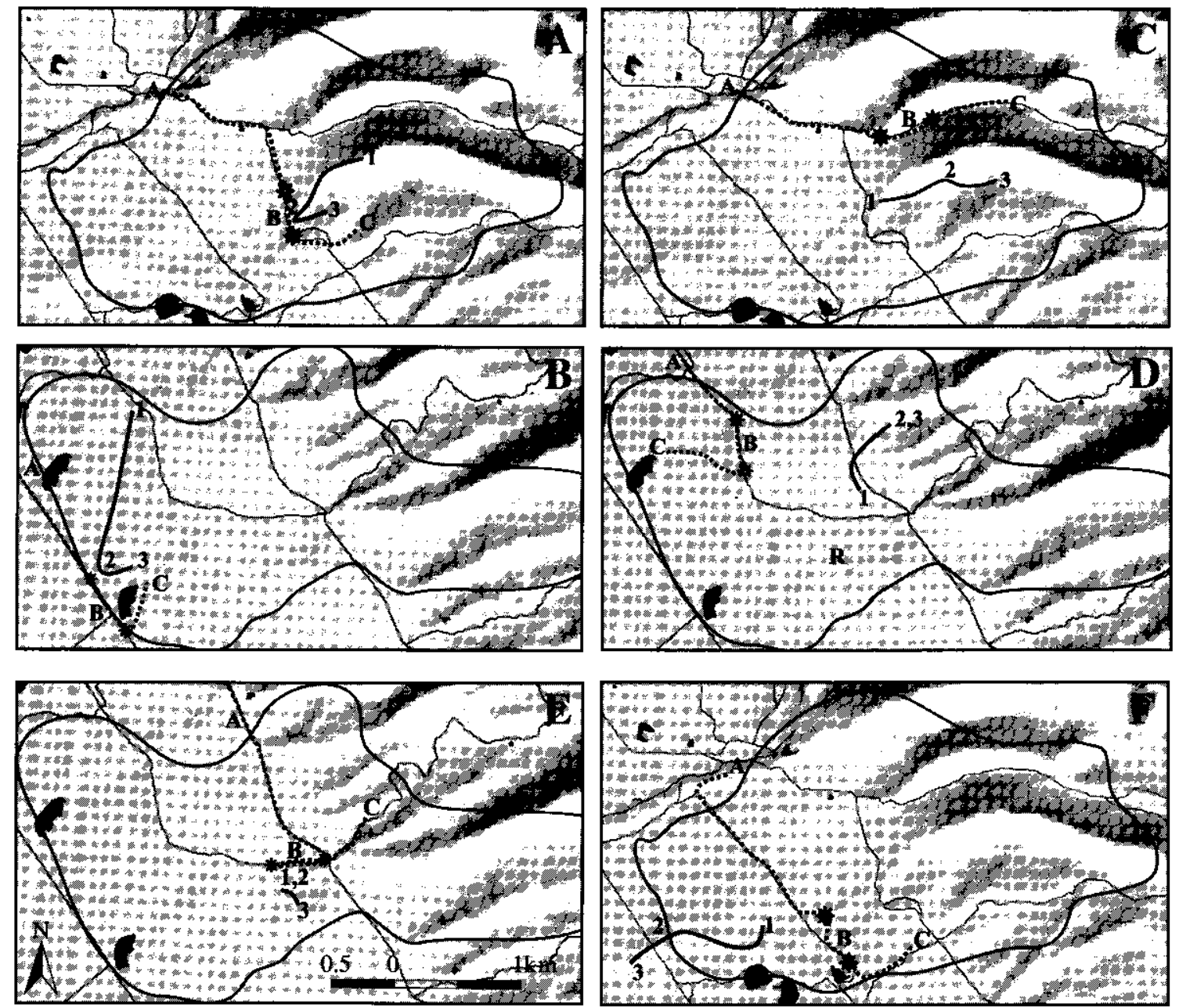

* camera location

$\mathbf{R}$ additional researcher

researcher path

coyote path

territory boundary

roads
1. coyote location at beginning of trial

2. coyote location during camera set up or removal

3. coyote location during observation session

A. researcher location at beginning of trial

B. researcher location during camera set up or removal

C. researcher location during observation session ever, there was no significant effect of age on photo-capture of radio-collared coyotes. Furthermore, alphas were not necessarily the oldest animals in the population.

Coyote vulnerability to photo-capture could have been influenced by the experience of having been captured in snares and radio-collared. As a result, these coyotes may have been relatively more wary of camera stations and consequently less likely to be photo-captured. However, this was not the case; radio-collared animals were not significantly underrepresented in the photo-captures. Over the 3-year period of 
Fig. 4. We were able to reliably identify coyotes from photographs. Most of the images were full side views of coyotes in flight with their ears turned toward the camera. Both color-coded radio-collars and individual numbers on ear tags were visible and were readily identified. There was no evidence to suggest that certain coyotes were able to avoid being photographed once they triggered a camera system. The short pulse delay setting ensured that once any animal triggered a camera system, it was photographed, as evidenced by our full-body images. Although coyotes were running away, they were still well within the camera's field of view when photographed.

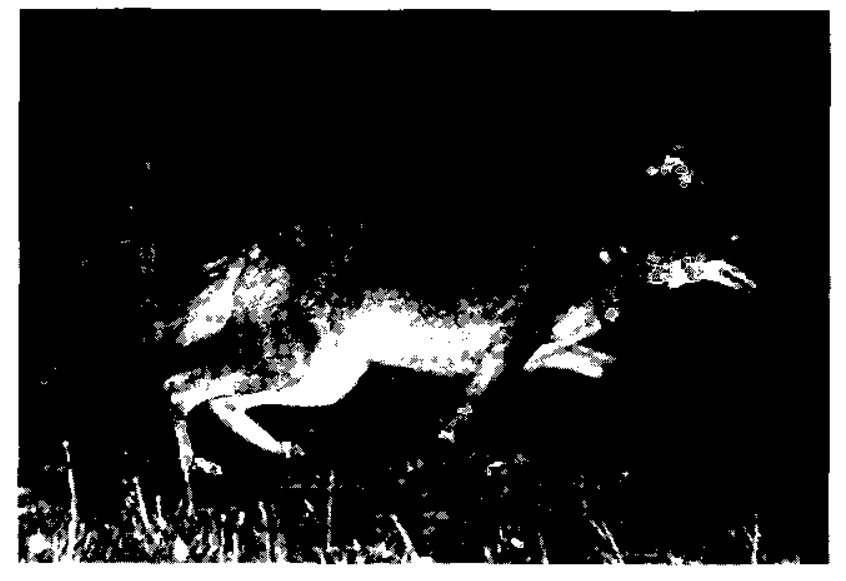

this study, both radio-collared and unradio-collared coyotes would have encountered camera stations. In addition, we were able to photograph both radio-collared and unradiocollared individuals multiple times, showing that "experienced" coyotes were vulnerable to photo-capture a second time. Alphas were significantly underrepresented in photocaptures even when only photographs of radio-collared animals were considered, implying that alpha coyotes either were better able to detect cameras than were coyotes of other status or, once they detected a camera, were more cautious toward it.

Why, then, were alphas not photo-captured within their territories but only outside them? The answer to this may be due in part to how alphas use space. Social status influences territory use and probably familiarity with the area of the territory (Sacks and Neale 2002). Since coyotes are likely to be more familiar with areas that they regularly use, responses toward novel objects should vary depending on the location of objects in relation to territory boundaries (Lehner 1976). Alphas are probably the only coyotes that are truly territorial in terms of defending and fully exploiting their space (Gese and Ruff 1997; Sacks and Neale 2002). While betas provide some help, alphas have been found to be responsible for the majority of territorial defense (Kamler and Gipson 2000; Gese 2001). Additionally, while betas generally adhere to the same territorial boundaries, their travels within a territory can be much more localized. At Dye Creek, one beta spent over 2 months in a single canyon before moving to a new location within the territory. Betas may also switch back and forth between being resident and transient (Sacks et al. 1999a). Therefore, betas may not be truly territorial in the sense that alphas are. In contrast, alphas travel their entire territories regularly (Sacks et al. 1999a; Sacks and Neale 2002). Thus, alphas are likely to be more familiar with their territories than betas. Since transients do not have specific territories and have the largest home ranges (Kamler and Gipson 2000), they are probably less familiar than either alphas or betas with the areas

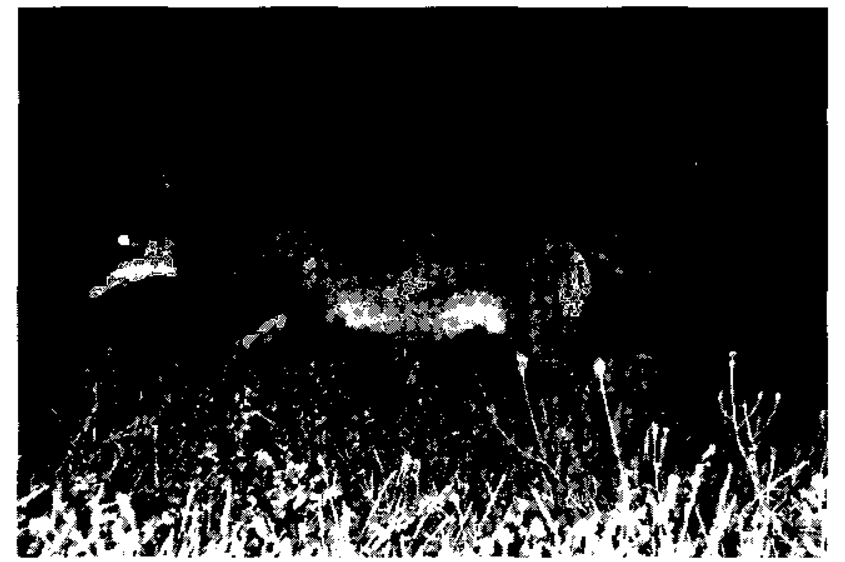

through which they travel. Thus, familiarity with home ranges likely decreases from alphas to betas to transients.

Greater familiarity with territorial space implies that alphas may have been better able to detect camera stations and were able to locate them sooner than other coyotes. This explanation assumes that alphas could effectively detect camera stations at night or else that they detected them all during daylight. Detection can occur by accidental encounter, by seeing the flash of the camera from a distance when another animal is photographed, by social learning, or by tracking human activity associated with construction and weekly check of camera stations. A coyote can then avoid subsequent encounters with the same camera either by detecting it again or by having learned its location. Adult coyotes, independent of status, probably possess a similar capability to sense objects by sight or smell. If alphas were better able than other adults to detect the cameras by sight or smell, we would have expected them to be able to avoid cameras outside their own territories as well. In fact, they should have been even more alert outside their territories where they were in less familiar surroundings (Camenzind 1978). It is possible that because of greater territory familiarity, alphas were more readily able to determine when an object was new or out of the ordinary within their territory boundaries. Alphas may also have well-developed cognitive maps (Peters 1975) by which they can remember multiple camera sites and avoid them even in the dark. This, however, does not adequately explain how alphas detected and avoided all camera sites within their territories at first encounter.

\section{Tracking human activity}

Alphas actively tracked human activity within their territories and presumably gained information about locations of camera stations as they were being set up. They did this either by approaching our location directly or by moving to a vantage point from where they could observe us (Fig. 3). In contrast, betas and transients did not track human activity. 
Approaches often required alphas to move long distances within their territories and they frequently approached close enough to be observed. This suggests that alphas may have been seen during the observation sessions at a higher rate than they were represented in the population. Additionally, alphas may have been sighted relatively more often because they generally move about more than betas and transients and may be more active during dawn and dusk hours. However, the ratio of alphas to betas and transients based on morning and evening observation sessions did not differ significantly from the ratio based on the known numbers of coyotes of different social status in the area.

That alphas used vantage points is suggested by their moving to locations that were in direct line of sight of the human activity. Distances from the researcher to vantage points ranged from approximately 0.5 to $2 \mathrm{~km}$. The greatest distances occurred when researchers were located in the plains areas and alphas moved to the overlooking foothills. Alphas generally stayed at these vantage points for the duration of the setup procedure and were often noted to be looking in our direction. Evidently, alphas could track more than one human at a time. During trials when another researcher was elsewhere in the territory, alphas were more likely to move to vantage points from where they could potentially observe both human incursions (Fig. 3D) and were not as likely to approach the camera station during its set up. This visual tracking was most likely facilitated by both the open habitat and the relatively small territory sizes at Dye Creek Preserve. However, while coyotes in more densely covered terrain may find it more difficult to visually track activity from a distance, they would also be able to approach more closely without being detected. Hence, coyotes inhabiting more densely covered terrain may be more likely to approach than move to vantage points. Alphas tracked human activity only within their own territory and the tracking generally continued as long as researchers were within the territory boundaries. This may explain why alphas were never photo-captured in their own territory but were vulnerable outside it.

Alphas approached more often when researchers were accompanied by a dog. These approaches were closer on average than those during the trials without the dog (to approximately $150 \mathrm{~m}$ versus $400 \mathrm{~m}$ ). The dog also elicited more vocal responses, making alphas much more obvious and potentially vulnerable. Betas and transients likewise demonstrated less caution when the dog was present. Both instances of betas watching the setup process occurred during dog trials, and transients were twice observed trotting alongside the researcher and dog at a distance of approximately $150 \mathrm{~m}$. Pups also were more likely to remain in the area and continue playing if a dog was present. However, dog presence at a camera station did not influence subsequent photo-captures. Alphas continued to avoid the cameras. Alpha coyotes probably approach and confront dogs to drive them off as they would do to coyotes intruding in their space. However, caution and avoidance prevailed when the dog was with a human.

\section{Wariness}

The finding that alphas track human activity during the construction of camera stations and subsequently avoid photo-capture suggests that these coyotes were cautious of camera stations because of their association with humans and not simply because they were novel. It is important to distinguish between wariness and neophobia. The term neophobia is used here to mean the initial avoidance or caution resulting from the novelty associated with an object, food, or odor in a familiar setting (Windberg and Knowlton 1990; Windberg 1996; Harris and Knowlton 2001). This is generally assumed to be a genetically fixed response that functions as a first line of defense against potentially harmful encounters with which the coyote has no previous experience. While the level of neophobia can be affected by the frequency with which an animal encounters novel objects (Mettke-Hofmann et al. 2002) and by previous experience with other objects (Pedersen 1994), neophobia is not a learned response. After the initial caution, however, habituation can occur with repeated exposure.

The concept of wariness as it applies to coyotes avoiding the threat of capture differs from neophobia in three fundamentally important ways. First, wariness includes caution toward familiar objects and familiar locations. At Dye Creek, coyotes continued to avoid cameras even after having been exposed to them for over 2 years. Although coyotes were most likely accustomed to having humans (hunters, cowboys, The Nature Conservancy personnel, and researchers) in their territories, they continued to track our activity throughout the trials. This was likely due to the intermittent capture of additional coyotes for a concurrent study. Wariness toward locations is suggested by the finding that after removal of an alpha by a trapper, its mate will subsequently avoid the area where the trapping or snaring occurred (Blejwas 2002). Second, wariness is affected by prior experience with capture. Alphas are harder to trap where they have previously been exposed to culling (Sacks et al. 1999b), and this does not seem to be the result of first removing those animals easiest to catch (Brand et al. 1995). In the present study, coyotes were first exposed to trapping about 18 months before the initial photo session. Prior experience with removal may sensitize coyotes in the area to human activity. On the other hand, wariness was reduced by close proximity of camera stations to preexisting human structures such as gates or power pylons where there was a longestablished pattern of human use. Third, wariness toward a situation can be due to its association with human presence and the threat of capture. Capture is an especially important threat because a single encounter can be fatal. The best way to avoid accidentally encountering a "trap" is to be aware of its location as soon as it is placed in position. Radio-collared alphas in this study did this by tracking human activity and associating devices such as camera stations with capture.

In conclusion, although all coyotes seemed to be wary of photo-capture, the way that wariness was expressed depended on status. Vulnerability was influenced both by camera location in relation to territory boundaries and by behaviors associated with status. Alphas were the only coyotes that actively tracked human activity within their own territories, suggesting that this behavior was responsible for their ability to detect and avoid cameras more efficiently. The necessity and responsibility of defending their territory 
may require and (or) produce greater vigilance, wariness, and familiarity that make alphas the least susceptible to photo-capture within their territories.

\section{Acknowledgements}

Funding and equipment were provided in large part by the USDA National Wildlife Research Center through cooperative agreements with the University of California at Berkeley (No. 7405-0235 CA). Special thanks go to B. Mitchell who shared background data collected for his Ph.D. dissertation at the University of California at Berkeley that made this study possible. We thank K. Blejwas, F. Knowlton, W. Longland, R. Rust, and B. Sacks for reviewing earlier drafts of the manuscript and D. Simpson for helping with coyote captures. Additionally, we thank the different agencies and staff working at Dye Creek Preserve for their cooperation and help: the Nature Conservancy, Multiple Use Managers, and Denny Land and Cattle Company.

\section{References}

Allen, S.H., Hastings, J.O., and Kohn, S.C. 1987. Composition and stability of coyote families and territories in ND. Prairie Nat. 19: $107-114$.

Andelt, W.F. 1985. Behavioral ecology of coyotes in south Texas. Wildl. Monogr. No. 94. pp. 1-45.

Bekoff, M. 1978. Coyotes: biology, behavior and management. Academic Press, New York.

Bekoff, M., and Wells, M.C. 1986. Social ecology and behavior of coyotes. Adv. Study Behav. 16: 251-338.

Blejwas, K.M. 2002. Selective removal of breeding coyotes: effects on sheep predation and the social, genetic, and spatial relationships of coyotes. Ph.D. dissertation, University of California, Berkeley.

Blejwas, K.M., Sacks, B.N., Jaeger, M.M., and McCullough, D.R. 2002. The effectiveness of selective removal of breeding coyotes in reducing sheep depredation. J. Wildl. Manag. 66: 451-462.

Brand, D.J., and Nel, J.A.J. 1997. Avoidance of cyanide guns by black-backed jackal. Appl. Anim. Behav. Sci. 55: 177-182.

Brand, D.J., Fairall, N., and Scott, W.M. 1995. The influence of regular removal of black-backed jackals on the efficiency of coyote getters. S. Afr. J. Wild1. Res. 25: 44-48.

Camenzind, F.J. 1978. Behavioral ecology of coyotes on the National Elk Refuge, Jackson, Wyoming. In Coyotes: biology, behavior, and management. Edited by M. Bekoff. Academic Press, New York. pp. 267-294.

Gantz, G.F. 1990. Seasonal movement patterns of coyotes in the bear River Mountains of Utah and Idaho. M.S. thesis, Utah State University, Logan.

Gese, E.M. 1999. Threat of predation: do ungulates behave aggressively towards different members of a coyote pack? Can. J. Zool. 77: 499-503.

Gese, E.M. 2001. Territorial defense by coyotes (Canis latrans) in Yellowstone National Park, Wyoming: who, how, where, when, and why. Can. J. Zool. 79: 980-987.

Gese, E.M., and Ruff, R.L. 1997. Scentmarking by coyotes, Canis latrans: the influence of social and ecological factors. Anim. Behav. 54: 1155-1166.

Gese, E.M., and Ruff, R.L. 1998. Howling by coyotes (Canis latrans): variation among social classes, seasons, and pack sizes. Can. J. Zool. 76: 1037-1043.
Gese, E.M., Rongstad, O.J., and Mytton, W.R. 1988. Home range and habitat use of coyotes in southeastern Colorado. J. WildJ. Manag. 52: 640-646.

Gese, E.M., Ruff, R.L., and Crabtree, R.L. 1996a. Social and nutritional factors influencing the dispersal of resident coyotes. Anim. Behav. 52: 1025-1043.

Gese, E.M., Ruff, R.L., and Crabtree, R.L. 1996b. Foraging ecology of coyotes (Canis latrans): the influence of extrinsic factors and a dominance hierarchy. Can. J. Zool. 74: 769-783.

Gier, H.T. 1968. Coyotes in Kansas. Kans. Agric. Exp. Stn. Bull. 393: $1-118$.

Gompper, M.E. 2002. Top carnivores in the suburbs? Ecological and conservation issues raised by colonization of north America by coyotes. Bioscience, 52: 185-190.

Harris, C.E. 1983. Differential behavior of coyotes with regard to home range limits. Ph.D. dissertation, Utah State University, Logan.

Harris, C.E., and Knowlton, F.F. 2001. Differential responses of coyotes to novel stimuli in familiar and unfamiliar settings. Can. J. Zool. 79: 2005-2013.

Kamler, J.F., and Gipson, P.S. 2000. Space and habitat use by resident and transient coyotes. Can. J. Zool. 78: 2106-2111.

Knowlton, F.F., Gese, E.M., and Jaeger, M.M. 1999. Coyote depredation control: an interface between biology and management. J. Range Manag. 52: 398-412.

Kucera, T.E., and Barrett. R.H. 1993. The trailmaster camera system for detecting wildlife. Wildl. Soc. Bull. 21: 505-508.

Lehner, P.N. 1976. Coyote behavior: implications for management. Wildl. Soc. Bull. 4: 120-126.

Lehner, P.N., Krumm, R., and Cringan, A.T. 1976. Tests for olfactory repellents for coyotes and dogs. J. Wildl. Manag. 40: 145150 .

Linhart, S.B., and Knowlton, F.F. 1967. Determining age of coyotes by tooth cementum layers. J. Wildl. Manag. 31: 362-365.

Messier, F., and Barrette, C. 1982. The social system of the coyote (Canis latrans) in a forested habitat. Can. J. Zool. 60: 17431753 .

Mettke-Hofmann, C., Winkler, H., and Leisler, B. 2002. The significance of ecological factors for exploration and neophobia in parrots. Ethology, 108: 249-272.

National Agricultural Statistics Service. 1995. Sheep and goat predator loss. U.S. Department of Agriculture, Washington, D.C.

Pedersen, V. 1994. Long-term effects of different handling procedures on behavioral, physiological, and production-related parameters in silver foxes. Appl. Anim. Behav. Sci. 40(3-4): 285296.

Peters, R. 1975. Mental maps in wolf territoriality. In The behavior and ecology of wolves. Proceedings of the Symposium on the Behavior and Ecology of Wolves, Annual Meeting of the Animal Behavior Society, Wilmington, N.C., May 1975. Edited by E. Klinghammer. Garland STPM Press, New York.

Sacks, B.N., and Neale, J.C.C. 2002. Foraging strategy of a generalist predator toward a special prey: coyote predation on sheep. Ecol. Appl. 12: 299-306.

Sacks, B.N., Jaeger, M.M., Neale, J.C.C., and McCullough, D.R. $1999 a$. Territoriality and breeding status of coyotes relative to sheep predation. J. Wildl. Manag. 63: 593-605.

Sacks, B.N., Blejwas, K.M., and Jaeger, M.M. 1999b. Relative vulnerability of coyotes to removal methods on a northern California ranch. J. Wildl. Manag. 63: 939-949.

Séquin, E.S. 2001. The influence of social status on coyote vulnerability to photo-capture. M.S. thesis, University of Nevada, Reno. 
Shivik, J.A., Jaeger, M.M., and Barrett, R.H. 1996. Coyote movements in relation to the spatial distribution of sheep. J. Wildl. Manag. 60: 422-430.

Till, J.A., and Knowlton, F.F. 1983. Efficacy of denning in alleviating coyote depredations upon domestic sheep. J. Wildl. Manag. 47: $1018-1025$.

Wagner, F.H. 1988. Predator control and the sheep industry. Regina Books, Claremont, Calif.

Wells, M.C., and Lehner, P.N. 1978. The relative importance of the distance senses in coyote behaviour. Anim. Behav. 26: 251-258.

Windberg, L.A. 1996. Coyote responses to visual and olfactory stimuli related to familiarity with an area. Can. J. Zool. 74: $2248-2253$.
Windberg, L.A., and Knowlton, F.F. 1988. Management implications of coyote spacing patterns in southern Texas. J. Wilds. Manag. 52: 632-640.

Windberg, L.A., and Knowlton, F.F. 1990. Relative vulnerability of coyotes to some capture procedures. Wildl. Soc. Bull. 18: 282290.

Woodruff, R.A., and Keller, B.L. 1982. Dispersal, daily activity and home range of coyotes in southeastern Idaho. Northwest Sci. 56: $199-207$

Worton, B.J. 1989. Kernel methods for estimating the utilization distribution in home range studies. Ecology, 70: 164-168. 